\title{
HEPATITIS C VIRUS E1 PROTEIN ENHANCES MACROPHAGE iNOS EXPRESSION IN VITRO
}

\section{Batkhishig Munkhjargal1,3, Bilguun Enkhtuvshin¹, Uranbileg Ulziisaikhan', Baljinnyam Tuvdenjamts $^{1,3}$, Khulan Unurbuyan ${ }^{1,3}$, Dolgorsuren Sandagdorj ${ }^{1}$, Tuul Baasandalai ${ }^{1}$, Baasansuren Enkhjargal', Tsogtsaikhan Sandag', Bilegtsaikhan Tsolmon², Enkhsaikhan Lkhagvasuren $^{1}$}

${ }^{1}$ Department of Immunology, School of Bio-Medicine, Mongolian National University of Medical Sciences, Ulaanbaatar, Mongolia

${ }^{2}$ Second State Central Hospital, Ulaanbaatar, Mongolia

${ }^{3}$ Institute of Medical Sciences, Mongolian National University of Medical Sciences, Ulaanbaatar, Mongolia

\author{
Corresponding Author \\ Enkhsaikhan Lkhagvasuren, PhD. \\ Department of Immunology, School of Bio-Medicine, Sukhbaatar district, Zorig Street, Ulaanbaatar, 14210 Mongolia \\ Tel: +976-89981001 \\ E-mail: enkhsaikhan@mnums.edu.mn
}

Running title: HCV E1 protein enhances macrophage iNOS expression in vitro.

Submitted date: Jan 20, 2021 


\section{Abstract}

\section{Objective:}

Hepatitis C virus (HCV) is a single-stranded RNA virus that causes chronic hepatitis, cirrhosis, and liver cancer. Approximately 170 million individuals are infected with HCV worldwide. The pathogenesis of HCV-associated liver injury is thought to be due to the host antiviral immune response, including the $\mathrm{T}$ cell response, and excessive production of proinflammatory cytokines, reactive oxygen species, and nitric oxide (NO).

Interferon- $\gamma($ IFN- $\gamma)$ is a key cytokine in the adaptive immune response that is primarily secreted from CD4+ T helper cells to induce cytotoxic T lymphocyte (CTL) cell response against $\mathrm{HCV}$ infection. Another important role of IFN- $\gamma$ is the activation of macrophages in the liver resulting in inhibition of viral replication and increased NO production.

Enhanced inducible nitric oxide synthase (iNOS) expression and NO production observed in the liver of HCV-infected patients is positively correlated with viral load and hepatic inflammation. $\mathrm{HCV}$-infected macrophages are major producers of NO in the liver. It is not completely understood how HCV proteins affect iNOS expression and what the role of IFN- $\gamma$ is in HCV protein expression in HCV-infected macrophages. In this study, we examined the effect of INF- $\gamma$ and HCV proteins on iNOS expression in the Raw264.7 cell line.

Results: Consistent with other studies, HCV core and NS5A proteins induced iNOS expression in macrophages. Moreover, HCV E1 protein-enhanced iNOS expression is highest in the presence and absence of IFN- $\gamma$ activation.

Conclusion: These results indicate that hepatitis C virus core, NS5A, E1 protein regulates iNOS protein expression in IFN- $\gamma$-activated and resting macrophage cell lines. These findings points to a future research direction for understanding the pathogenesis of HCV-related liver inflammation.

Key words: HCV, iNOS, IFN- $\gamma$, RAW264.7

\section{Introduction}

Hepatitis $\mathrm{C}$ virus (HCV) is a positive-strand RNA virus belonging to the Flaviviridae family, which has established chronic infection in around 170 million human carriers worldwide [1]. Increasing evidence suggests that nitric oxide (NO) is an important factor in controlling viral infection by affecting the early antiviral immune response in HCV pathogenesis [2]. In the liver of HCV-infected patients, it has been reported that inducible nitric oxide iNOS) expression and excessive local nitric oxide production, which is positively correlated with viral load, produce hepatic inflammation and tissue damage[3].

In many viral infections, iNOS expression appears to be regulated directly by the virus itself or indirectly via interferon- $\gamma($ IFN- $\gamma)$ induction $[4,5]$.

IFN- $\gamma$ is the primary mediator of HCV-specific antiviral T-cell responses and strongly inhibits HCV replication in vitro [6]. IFN- $\gamma$ is known to upregulate the expression of inducible nitric oxide synthase (iNOS) in monocytes and macrophages, resulting in increased NO production [7]. However, the precise IFN- $\gamma$ effect on $\mathrm{HCV}$ protein expression and crosstalk between HCV proteins and IFN- $\gamma$ for induction of iNOS expression is not clear.

The primary source of nitric oxide in a liver is activated Kupffer cells (KC) and hepatocytes [8]. It has been shown that HCV proteins regulate iNOS expression and NO production in various cell systems. Many studies have reported that $\mathrm{HCV}$ core and non-structural proteins enhance NO production in hepatocytes and endothelial cells. However, there is an inconsistency regarding which 
viral proteins are responsible because some authors have shown that the core and NS5A proteins are sufficient for iNOS induction in activated KCs. In contrast, Lee et al. found that HCV core protein inhibits NO production in cultured Raw264.7 and J774 cell lines [2,9].

To understand these differences, in this study we examined the effects of HCV proteins on iNOS expression in IFN- $\gamma$-activated and resting-state-macrophages.

\section{Materials and Methods}

\section{Cell culture}

The murine macrophage cell line RAW264.7 (Core laboratory, MNUMS, Ulaanbaatar Mongolia) was used in this study. RAW264.7 cells were cultured in RPMI 1640 (Cat: 12-702F from Lonza Pharma \& Biotech, USA) supplemented with 10\% inactivated fetal calf serum (FCS) (Cat: a3520501 Thermo Fisher Scientific Inc, USA), an 1\% antibiotic mixture (Cat: 15140-122 from Thermo Fisher Scientific Inc, USA). Cells were incubated at $37^{\circ} \mathrm{C}$ and humidified in $5 \% \mathrm{CO} 2$ until cell growth reached $85 \%$ of the culture plates' surface area.

\section{Transfection and IFN- $\gamma$ treatment}

The cells were seeded in a 6-well plate and were cultured until they reached a confluence of $70 \%$. The culture was starved of nutrients by with holding the serum overnight before transfection. Transfection of $1 \mu \mathrm{g}$ pHCV-Core, pHCV-NS5A and pHCV-E1 (Cat: VG40278-UT, VG40284-UT, VG40279-UT from Sino biological, HK) plasmids were performed in separate wells using Lipofectamine 3000 (Cat: L3000001 from Invitrogen, USA) and cultured in a complete medium for 48 hours. Half of the cultures were then treated with IFN- $\gamma(25 \mathrm{ng} / \mathrm{ml})$ (Cat: 315-05-100 from PeproTech Rocky Hill, USA) for 18 hours at 48 hours post-transfection[10].

\section{Immunoblotting}

The cells were lysed using RIPA buffer supplemented with protease and phosphatase inhibitors (Lot: 06131601 from Thermo Fisher Scientific Inc, USA). The protein concentration was measured by Pierce BCA protein assay kit (Cat: 23228 from Thermo Fisher Scientific Inc, USA) according to the manufacturer's instruction. Proteins were resolved by SDS electrophoresis and transferred onto nitrocellulose membranes. The membrane was incubated for 24 hours with the HCV anti-core, antiE1, anti-NS5A (Cat: ab18929, ab13833, ab54555 from Abcam, UK) anti-iNOS and anti-p38 antibodies (Cat: 2982S, 9215S from Cell Signaling Technology, USA). The blot was then incubated with the corresponding HRP-conjugated secondary antibodies (Cell Signaling Technology, USA Cat: 111-035-003). The proteins were visualized using the ECL system (Lot OA183335 from Pierce, Rockford, USA). Total p38 expression was used as an internal control [11].

\section{Ethical statement}

The study was approved by The Ministry of Health (MoH)-Medical Ethics Committee (№80).

\section{Results}

\section{Effect of IFN- $\gamma$ on the HCV proteins expression in macrophage.}

Kupffer cells (KCs) are liver macrophages and represent 15 to 20\% of the total liver cell population. Classical type macrophage activation against HCV occurs by $\mathrm{T}$ cell-mediated immunity in the presence of IFN- $\gamma$. It has been shown that IFN- $\gamma$ suppresses HCV replication through activation of various ISG genes. However, IFN- $\gamma$ 's direct impact on HCV protein expression is not well studied. 
We examined the effect of IFN- $\gamma$ on HCV proteins using transient transfection of HCV core, NS5A and E1 protein-coding plasmids. The experimental procedure for testing the effect of IFN- $\gamma$ on HCV protein expression is as outlined in (Figure 1A). Raw264.7 cells were seeded 2 days before the transient transfection with equal amounts of HCV-core, NS5A and E1 coding plasmids driven by a CMV promoter. HCV E1, NS5A and core proteins are detected around $31 \mathrm{kD}, 56 \mathrm{kD}$ and $21 \mathrm{kD}$, respectively, by Western blot (Figure $1 \mathrm{~B}$ ). Our Western blot results proved (Figure 1B) that we successfully transfected DNA to RAW264.7 cells. IFN- $\gamma$ treatment was performed at 2 days posttransfection to test the HCV protein expression in response to IFN- $\gamma$-mediated macrophage activation. An increase in HCV E1 protein expression was observed when the culture medium was supplemented with IFN- $\gamma$. In contrast, HCV core and NS5A expressions were inhibited by IFN- $\gamma$ treatment (Figure 1B).
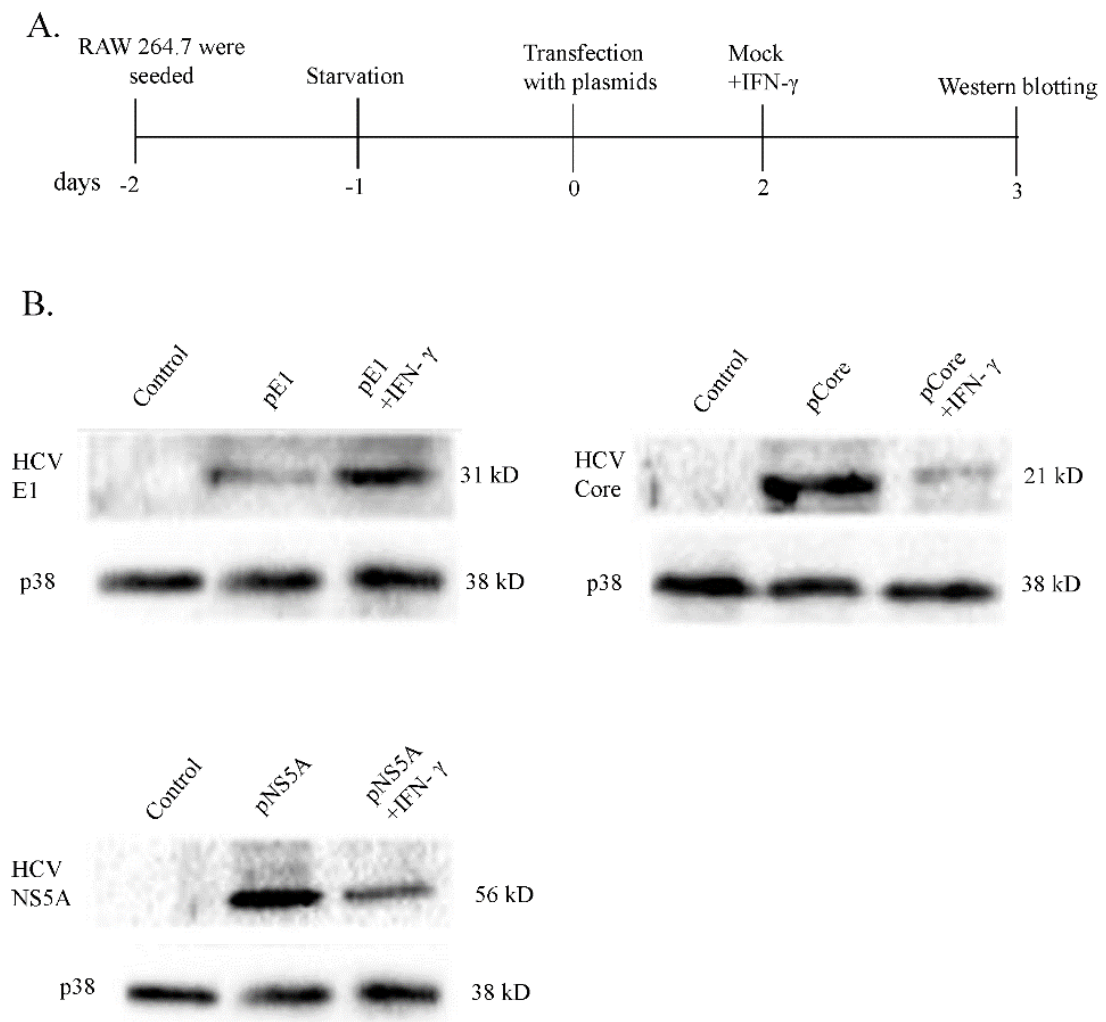

Figure 1. Effect of IFN $\gamma$ on the HCV proteins expression in macrophages

(A) Illustration showing the experimental design. (B) Non-transfected RAW264.7 cells served as a negative control (Lane 1). The expression of HCV Core, NS5A, E1 protein in RAW264.7 cells was detected by Western Blot which indicates successful transfection (Lane 2). HCV core, NS5A, and E1 protein expressions were examined after IFN- $\gamma$ treatment (Lane 3). Total p38 expression served as a loading control. 


\section{HCV E1 protein modulates iNOS expression in Raw264.7 cells}

It is well known that HCV infection upregulates iNOS expression in vitro and in vivo, albeit the responsible HCV protein for increased iNOS expression in macrophages remains elusive. The increased iNOS expression and NO production induce liver tissue damage and have no impact on HCV replication and viral protein expression. Next, we asked how IFN- $\gamma$ mediated the HCV--induced upregulation of iNOS by the host immune response. The experimental procedure is outlined_(Figure 2A.). The RAW264.7 cells were starved of serum 24 hours before transfection to synchronize all cells into the same phase of the cell cycle and to eliminate possible noises of iNOS expression. IFN- $\gamma$ and mock treatments were done at 2 days post-transfection with viral protein-coding plasmids. The expression of iNOS protein was detected by Western Blot using an anti-iNOS antibody at day 3 posttransfection. Mock-transfected resting RAW264.7cells showed no detectable iNOS expression by western blot (Lane 1). IFN- $\gamma$ treatment enhanced iNOS expression slightly (compare Lane 1 and Lane 2). HCV core transfection resulted in marginally increased expression of iNOS while no detectable signal was observed in the NS5A transfection (compare Lane 3 and 7 to Lane 1). To our surprise, HCV E1 transfection increased iNOS expression (compare Lane 1 and 5). The combination of HCV proteins transfection and IFN- $\gamma$ mediated macrophage activation induced more iNOS expression compared to IFN- $\gamma$ treatment alone (compare Lane 4, 6 and 8 to Lane 2). iNOS expression was markedly increased when with HCV E1 plasmid transfection was combined with IFN- $\gamma$ treatment (compare Lanes 5 and 6) (Figure 2B).

A

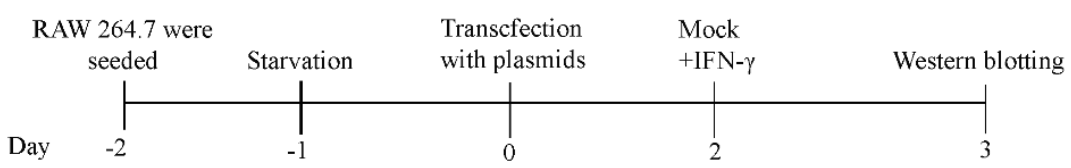

B

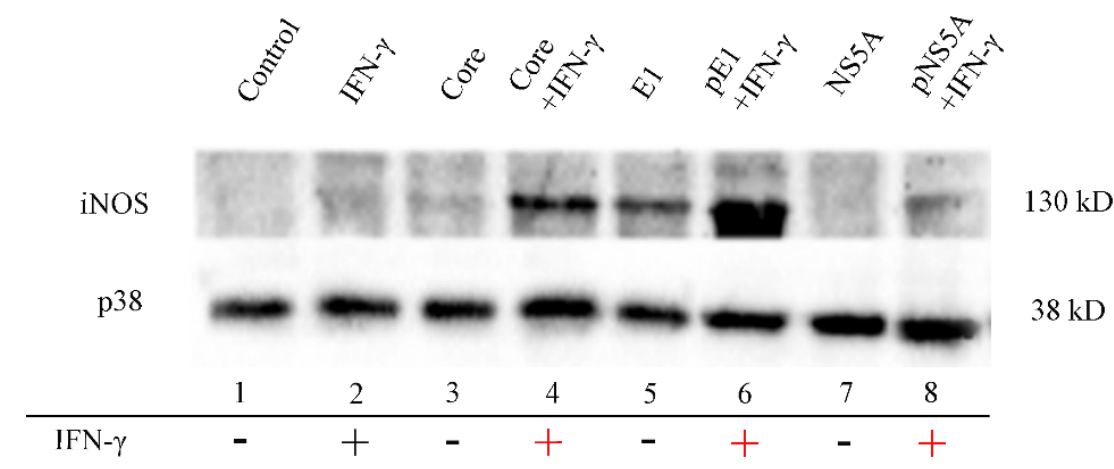


Figure 2. HCV proteins modulate iNOS expression in Raw264.7 cells

(A) Illustration showing the experimental design. (B) iNOS expression in Raw264.7 cells was detected by Western blot analysis using anti-iNOS antibodies (mouse). Non-transfected RAW264.7 cells served as a negative control (Lane 1). Non-transfected cells were activated by $25 \mathrm{ng} / \mathrm{ml}$ IFN- $\gamma$ (Lane 2). iNOS expression in RAW264.7 cells was detected by Western Blot after transfection with pHCV-Core, pHCV-E1 and pHCV-NS5A plasmids without IFN- $\gamma$ activation (Lanes 3,5,7). HCV core, E1, NS5A protein-expressing RAW264.7 cells were activated by $25 \mathrm{ng} / \mathrm{ml}$ IFN- $\gamma($ Lanes $4,6,8)$. Total p38 expression served as a loading control. $(+)$ treated with IFN- $\gamma,(-)$ untreated with IFN- $\gamma$

\section{Discussion}

In this study, we revisited the relationship between IFN- $\gamma$, HCV proteins and iNOS expression in macrophages using a transient transfection system. Our Western blot results proved successful transfection of HCV E1, NS5A and core protein-coding plasmids (Figure 1B). IFN- $\gamma$ treatment on HCV core and NS5A protein-expressing RAW264.7cells showed inhibition of viral protein expression. In contrast, HCV E1 protein expression was increased when cells were treated with IFN$\gamma$ (Figure 1B).

iNOS expression were influenced positively increases transfection of HCV proteins with the IFN- $\gamma$ treatment. Surprisingly, we found that HCV E1 protein upregulates iNOS expression in vitro most strongly (Figure 2B).

The HCV protein's effect on NO production and iNOS expression has been studied in various cell systems in earlier reports (Table 1). HCV core protein increased iNOS expression in the studies using CHL, Raji, HepG2, primary human conjunctival fibroblast, human corneal epithelial cell lines and mouse liver [12-17]. In contrast, iNOS expression was downregulated by HCV core protein in the in vitro studies using Raw264.7 and J774 cell lines and coculture system of LSECs+HepG2 [18,19]. The opposite effect of HCV core protein on iNOS expression between this study and earlier reports can be related to several possibilities: 1)We detected increased iNOS expression when HCV core protein was treated together with IFN- $\gamma$ in Raw264.7 cells, while earlier reports observed decreased NO production when co-treated with HCV core, LPS and Zymosan in Raw264.7 and J774 cells. 2) Earlier reports used the coculture system of LSECs+HepG2 to study the effect of HCV core protein on iNOS expression.-_Using a different cell culture system could be a cause of opposite observations. iNOS expression was upregulated by HCV NS5A protein in HepG2 and CHL cell systems [12,20]. 


\begin{tabular}{|c|c|c|c|c|}
\hline Author & Experimental model & HCV protein & $\begin{array}{l}\text { iNOS } \\
\text { expression }\end{array}$ & $\begin{array}{l}\text { NO } \\
\text { production }\end{array}$ \\
\hline Keigo Machida et al. [17] & Mouse liver & Core & Upregulated & \\
\hline $\begin{array}{l}\text { Maria Victoria Garcia et } \\
\text { al. [12] }\end{array}$ & CHL cell line & $\begin{array}{l}\text { Core } \\
\text { NS5A }\end{array}$ & $\begin{array}{l}\text { Upregulated } \\
\text { Upregulated }\end{array}$ & \\
\hline Keigo Machida et al. [13] & Raji cell & Core & Upregulated & \\
\hline $\begin{array}{l}\text { Susana de Lucas et } \\
\text { al.[15] }\end{array}$ & HepG2 & Core & Upregulated & \\
\hline Chu Hee Lee et al.[18] & $\begin{array}{l}\text { Raw } 264.7 \text { and } \\
\text { J774 }\end{array}$ & Core & & Downregulated \\
\hline Li-Jie Sun et al.[19] & LSECs+HepG2 & Core & & Downregulated \\
\hline $\begin{array}{l}\text { Ayilam Ramachandran } \\
\text { Rajalakshmy et al. [15] }\end{array}$ & $\begin{array}{l}\text { Primary human conjunctival } \\
\text { fibroblasts }\end{array}$ & Core & Upregulated & Upregulated \\
\hline $\begin{array}{l}\text { Yong-Fang Jiang et } \\
\text { al.[20] }\end{array}$ & HepG2 & NS5A & Upregulated & \\
\hline $\begin{array}{l}\text { Ayilam Ramachandran } \\
\text { Rajalakshmy et al. [16] }\end{array}$ & $\begin{array}{l}\text { Human corneal epithelial } \\
\text { cell line }\end{array}$ & Core & Upregulated & Upregulated \\
\hline
\end{tabular}

\section{Table 1. Previous reports of HCV protein's effect on NO production and iNOS expression}

We also found that HCV NS5A could stimulate iNOS expression in the Raw264.7 cell line. We were unable to find any studies about HCV E1 influence on iNOS expression in macrophages in our literature review (Table 1). Approximately up to 85\% of acute HCV infections result in persistent infection and can lead to life--threatening chronic conditions, including cirrhosis and hepatocellular carcinoma [21]. The mechanism of chronicity is explained by an insufficient HCV-specific CTL response, suppressed type 1 helper $\mathrm{T}$ cell response and generation of viral escape mutations [22,23].

Frese et al. demonstrated HCV viral protein synthesis and replication were not suppressed by increased iNOS expression and NO in hepatocytes. They also reported that in iNOS-deficient mice, increased production of NO might weaken T cell antiviral responses by impairing $\mathrm{T}$ helper 1 cell activity, leading the virus to overcome the pressure of the T cell immunity [24]. Viral escape mutations are frequently another important reason for viral persistence in HCV infection, and evidence suggests that NO could play a role in this scenario by accelerating the mutation rate of HCV RNA during viral infection in vivo [23]. What could then be the HCV E1 protein's role in the pathogenesis of HCV persistence? Is it possible that HCV E1 protein, driven iNOS expression, may play a role in HCV persistence? HCV E1 protein expression is increased when IFN- $\gamma$ (T helper I cytokine) is added (Figure 3). HCV E1 protein enhances iNOS expression in IFN- $\gamma$ activated macrophages. Enhanced iNOS expression resulted in excessive NO production in Kupffer cells. It may be that the HCV E1 protein indirectly modulates T helper 1 cell activity and accelerates HCV mutation rate (Figure 3). The HCV E1 protein allows HCV to escape and weaken B and T cell immune response.

In summary, HCV core and NS5A proteins induce iNOS expression when combined together with IFN- $\gamma$. IFN- $\gamma$ alone inhibited the expression of those viral proteins. However, HCV E1 protein strongly induced iNOS expression with or without IFN- $\gamma$. Surprisingly, IFN- $\gamma$ treatment further elevated HCV E1 protein levels. This is the first report to our knowledge that HCV E1 protein drives enhanced expression of iNOS in the macrophage cell line. Our results clarify there is crosstalk between HCV proteins and iNOS expression in the background of IFN- $\gamma$ treatment. HCV E1-induced 
iNOS expression may modulate HC-associated tissue damage pathogenesis and viral persistence. These findings update our understanding of HCV pathogenesis and HCV persistence.

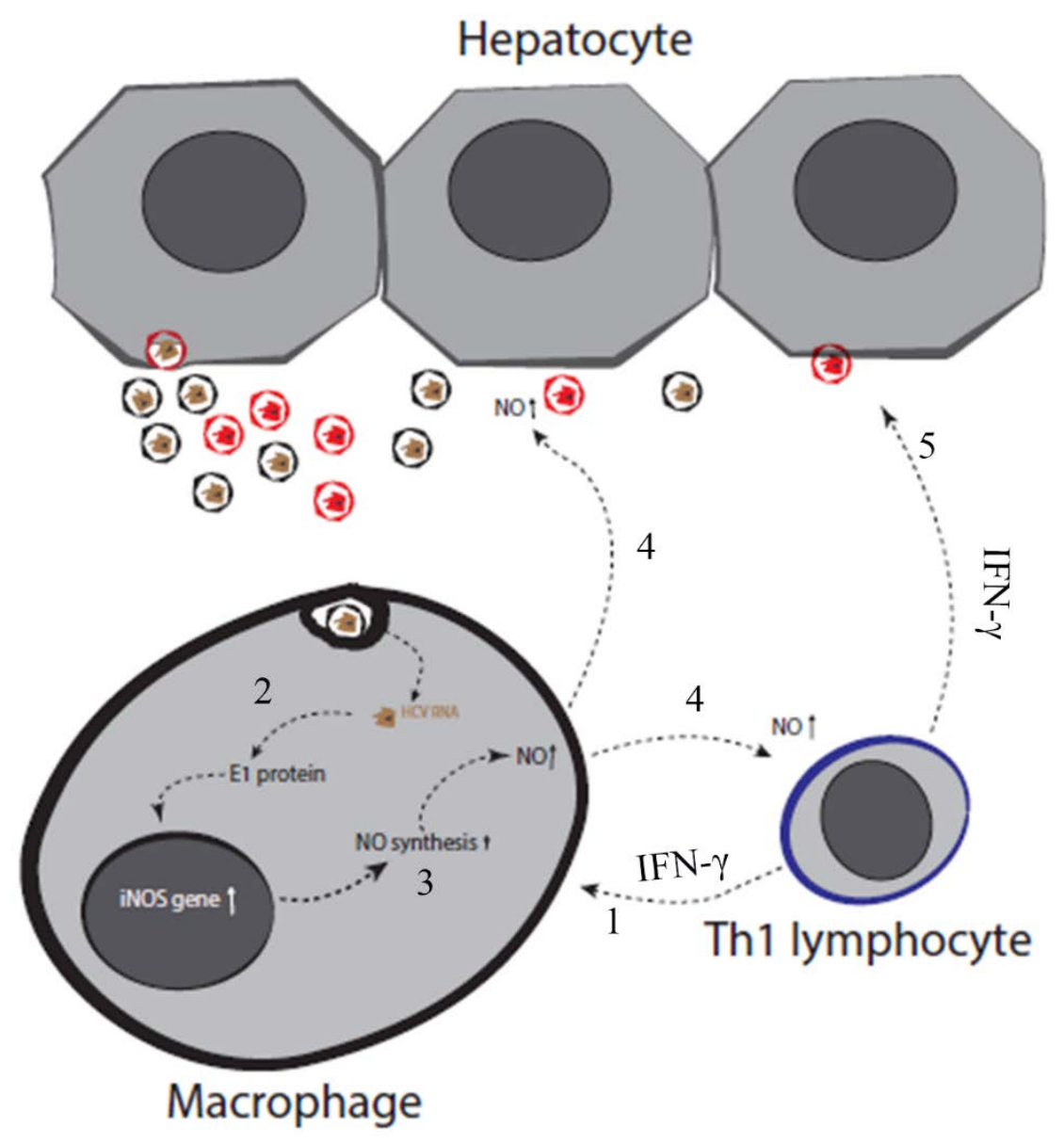

Figure 3. Possible mechanism of HCV E1 protein role on HCV persistence

$\mathrm{HCV}$, viral proteins, liver cells and signalling molecules involved in the pathogenesis of $\mathrm{HCV}$ persistence are illustrated. HCV persistence mechanism is generally explained by suppressed T helper 1 response and viral escape mutations. Nitric oxide induces weakens $\mathrm{T}$ helper 1 response and accelerates virus mutations (illustrated by block arrow, step 4, 5) (references). IFN- $\gamma$ secreted from HCV specific T helper 1 lymphocyte induces HCV E1 protein expression in HCV-infected Kupffer cells (step 1). HCV E1 enhances iNOS expression in Kupffer cells (step 2). IFN- $\gamma$ activated HCV E1 protein in Kupffer cells results in a further increase of iNOS expression (step 3). Excessive nitric oxide produced from HCV E1-derived iNOS activation weakens the T helper 1 response (step 4) and leads to the generation of escape mutations (step 5). 


\section{Conflict of Interest}

The authors declare no conflicts of interest.

\section{Acknowledgments}

The research funding was provided by the Mongolian Foundation for Science and Technology and the Ministry of Education, Culture, Science and Sports of Mongolia (Basic research grant: 2018/39). We thank Lkhagvasuren Damdindorj for technical support. We are grateful to Dr. Ron Anderson for the critical reading of the manuscript.

\section{References}

1. Bacon BR, Khalid O. New therapies for hepatitis C virus infection. Mo Med. 2011 JulAug;108(4):255-9. PMID: 21905441; PMCID: PMC6188416.

2. Majano PL, Garcia-Monzon C. Does nitric oxide play a pathogenic role in hepatitis C virus infection? Cell Death Differ. 2003 Jan;10 Suppl 1:S13-5. doi: 10.1038/sj.cdd.4401115. PMID: 12655339.

3. Mihm S, Fayyazi A, Ramadori G. Hepatic expression of inducible nitric oxide synthase transcripts in chronic hepatitis $C$ virus infection: relation to hepatic viral load and liver injury. Hepatology. 1997 Aug;26(2):451-8. doi: 10.1002/hep.510260228. PMID: 9252158.

4. Hang do TT, Song JY, Kim MY, Park JW, Shin YK. Involvement of NF-кB in changes of IFN- $\gamma$-induced CIITA/MHC-II and iNOS expression by influenza virus in macrophages. Mol Immunol. 2011 May;48(9-10):1253-62. doi: 10.1016/j.molimm.2011.03.010. Epub 2011 Apr 8. PMID: 21481937..

5. Remy MM, Sahin M, Flatz L, Regen T, Xu L, Kreutzfeldt M, Fallet B, Doras C, Rieger T, Bestmann L, Hanisch UK, Kaufmann BA, Merkler D, Pinschewer DD. Interferon- $\gamma$-Driven iNOS: A Molecular Pathway to Terminal Shock in Arenavirus Hemorrhagic Fever. Cell Host Microbe. 2017 Sep 13;22(3):354-365.e5. doi: 10.1016/j.chom.2017.07.008. Epub 2017 Aug 17. PMID: 28826838.

6. Schweyer S, Mihm S, Radzun HJ, Hartmann H, Fayyazi A. Liver infiltrating T lymphocytes express interferon gamma and inducible nitric oxide synthase in chronic hepatitis $\mathrm{C}$ virus infection. Gut. 2000 Feb;46(2):255-9. doi: 10.1136/gut.46.2.255. PMID: 10644322; PMCID: PMC1727815.

7. Tötemeyer S, Sheppard M, Lloyd A, Roper D, Dowson C, Underhill D, Murray P, Maskell D, Bryant C. IFN-gamma enhances production of nitric oxide from macrophages via a mechanism that depends on nucleotide oligomerization domain-2. J Immunol. $2006 \mathrm{Apr}$ 15;176(8):4804-10. doi: 10.4049/jimmunol.176.8.4804. PMID: 16585574.

8. Wang YY, Chen MT, Hong HM, Wang Y, Li Q, Liu H, Yang MW, Hong FF, Yang SL. Role of Reduced Nitric Oxide in Liver Cell Apoptosis Inhibition During Liver Damage. Arch Med Res. 2018 May;49(4):219-225. doi: 10.1016/j.arcmed.2018.09.001. Epub 2018 Sep 27. PMID: 30269965.

9. Lee CH, Choi YH, Yang SH, Lee CW, Ha SJ, Sung YC. Hepatitis C virus core protein inhibits interleukin 12 and nitric oxide production from activated macrophages. Virology. 2001 Jan 5;279(1):271-9. doi: 10.1006/viro.2000.0694. PMID: 11145908.

10. Dolgorsuren Sandagdorj1, Batkhishig Munkhjargal1, Baasansuren Enkhjargal1, Baljinnyam Tuvdenjamts13, Enkhjin Zorigt1, Budjav Jadamba1, Altanshagai Chinbat1, Khongorzul Samdankhuu4, Ulziisaikhan Jambalganii1, Batsuren Boldbaatar1, Tsogtsaikhan Sandag1, Bilegtsaikhan Tsolmon2, Enkhsaikhan Lkhagvasuren1. Regulating Action of in Vitro 
Hepatitis C Virus Infection on Interferon-Induced Interferon Stimulating Genes in Murine Macrophages, Cent Asian J Med Sci 2018;4:25-34. doi.org/10.24079/CAJMS.2018.03.004

11. Tsolmongyn B, Koide N, Jambalganiin U, Odkhuu E, Naiki Y, Komatsu T, Yoshida T, Yokochi T. A Toll-like receptor 2 ligand, Pam3CSK4, augments interferon- $\gamma$-induced nitric oxide production via a physical association between MyD88 and interferon- $\gamma$ receptor in vascular endothelial cells. Immunology. 2013 Nov;140(3):352-61. doi: 10.1111/imm.12147. PMID: 23826757; PMCID: PMC3800440.

12. García-Mediavilla MV, Sánchez-Campos S, González-Pérez P, Gómez-Gonzalo M, Majano PL, López-Cabrera M, Clemente G, García-Monzón C, González-Gallego J. Differential contribution of hepatitis C virus NS5A and core proteins to the induction of oxidative and nitrosative stress in human hepatocyte-derived cells. J Hepatol. 2005 Oct;43(4):606-13. doi: 10.1016/j.jhep.2005.04.019. PMID: 16112247.

13. Machida K, Cheng KT, Sung VM, Lee KJ, Levine AM, Lai MM. Hepatitis C virus infection activates the immunologic (type II) isoform of nitric oxide synthase and thereby enhances DNA damage and mutations of cellular genes. J Virol. 2004 Aug;78(16):8835-43. doi: 10.1128/JVI.78.16.8835-8843.2004. PMID: 15280491; PMCID: PMC479064.

14. de Lucas S, Bartolomé J, Amaro MJ, Carreño V. Hepatitis C virus core protein transactivates the inducible nitric oxide synthase promoter via NF-kappaB activation. Antiviral Res. 2003 Oct;60(2):117-24. doi: 10.1016/j.antiviral.2003.08.006. PMID: 14638407.

15. Rajalakshmy AR, Malathi J, Madhavan HN, Srinivasan B, Iyer GK. Hepatitis C virus core and NS3 antigens induced conjunctival inflammation via toll-like receptor-mediated signaling. Mol Vis. 2014 Sep 25;20:1388-97. PMID: 25352745; PMCID: PMC4173667.

16. Rajalakshmy AR, Malathi J, Madhavan HN. HCV core and NS3 proteins mediate toll like receptor induced innate immune response in corneal epithelium. Exp Eye Res. 2014 Nov;128:117-28. doi: 10.1016/j.exer.2014.09.011. Epub 2014 Oct 1. PMID: 25280963.

17. Machida K, Tsukamoto H, Liu JC, Han YP, Govindarajan S, Lai MM, Akira S, Ou JH. c-Jun mediates hepatitis $\mathrm{C}$ virus hepatocarcinogenesis through signal transducer and activator of transcription 3 and nitric oxide-dependent impairment of oxidative DNA repair. Hepatology. 2010 Aug;52(2):480-92. doi: 10.1002/hep.23697. PMID: 20683948; PMCID: PMC3107125.

18. Lee CH, Choi YH, Yang SH, Lee CW, Ha SJ, Sung YC. Hepatitis C virus core protein inhibits interleukin 12 and nitric oxide production from activated macrophages. Virology. 2001 Jan 5;279(1):271-9. doi: 10.1006/viro.2000.0694. PMID: 11145908.

19. Sun LJ, Yu JW, Shi YG, Zhang XY, Shu MN, Chen MY. Hepatitis C virus core protein induces dysfunction of liver sinusoidal endothelial cell by down-regulation of silent information regulator 1. J Med Virol. 2018 May;90(5):926-935. doi: 10.1002/jmv.25034. Epub 2018 Feb 2. PMID: 29350417.

20. Jiang YF, He B, Li NP, Ma J, Gong GZ, Zhang M. The oncogenic role of NS5A of hepatitis $\mathrm{C}$ virus is mediated by up-regulation of survivin gene expression in the hepatocellular cell through p53 and NF-кB pathways. Cell Biol Int. 2011 Dec;35(12):1225-32. doi: 10.1042/CBI20110102. PMID: 21612579.

21.Leblebicioglu H, Bayirli D, Esen S, Sunbul M, Eroglu C. Treatment of acute hepatitis C virus infection with interferon-alpha $2 \mathrm{~b}$ and ribavirin: case report and review of the literature. Ann Clin Microbiol Antimicrob. 2002;1:3. Published 2002 Oct 14. doi:10.1186/1476-0711-1-3

22. Koziel MJ. Cellular immune responses against hepatitis C virus. Clin Infect Dis. 2005 Jul 1;41 Suppl 1:S25-31. doi: 10.1086/429492. PMID: 16265610.

23. Larrubia JR, Moreno-Cubero E, Lokhande MU, García-Garzón S, Lázaro A, Miquel J, Perna $\mathrm{C}$, Sanz-de-Villalobos E. Adaptive immune response during hepatitis $\mathrm{C}$ virus infection. World 
J Gastroenterol. 2014 Apr 7;20(13):3418-30. doi: 10.3748/wjg.v20.i13.3418. PMID: 24707125; PMCID: PMC3974509.

24. Frese M, Schwärzle V, Barth K, Krieger N, Lohmann V, Mihm S, Haller O, Bartenschlager R. Interferon-gamma inhibits replication of subgenomic and genomic hepatitis $\mathrm{C}$ virus RNAs. Hepatology. 2002 Mar;35(3):694-703. doi: 10.1053/jhep.2002.31770. PMID: 11870386. 